\title{
The Exploitation of the Sea.
}

TWO very important documents bearing on the subject of the rational exploitation of fishing grounds have recently become available. The first is the report to the Minister of Agriculture and Fisheries of the British delegates who attended the meeting of the International Council for the Exploration of the Sea, held at Copenhagen in September last. The other is the Report of the Danish Biological Station (xxix., 1922). Both papers are of very great interest.

The British official report emphasises the practical nature of the work of the Council and gives an account of its organisation. There are four sections (hydrography, plankton, statistics, and fish). The work of the fish section is carried out by committees, and those which deal with the investigation of the herring, cod and haddock, and of the biology of the Atlantic slope are of great interest to British workers. Programmes of the investigations adopted by these committees are given in the report. One important committee, that on the plaice fisheries, has now completed its work, and the recommendations made by it have been approved by the Council and are given in full. These are that the parts of the North Sea situated (I) between the Continental coast and the 12 -fathom line from N. lats. $52^{\circ}$ to $56^{\circ}$, and (2) between the 12 -fathom and the $\mathbf{I}_{5}$-fathom line, be closed to steam trawlers and motor vessels of more than 50 h.p., the inner zone throughout the entire year and the outer one during the months July to March. No size-limits with respect to the fish caught are recommended. The Council recognises the difficulty of enforcing these measures without the sympathetic support of the fishing industry, but it regards this as a matter for the concern of the governments of the participating countries. It is considered that the adhesion of Germany to such a scheme of regulation will be essential. The Council advises the continuance of observations and the review of the whole proceedings after three years have elapsed.

The meaning of the impoverishment of a plaice fishing ground is examined by Dr. C. G. J. Petersen in the second of the reports noticed. Since I893 this distinguished Danish zoologist has studied the fisheries in the Limfiord and in the adjacent seas. In 1893 the old styles of plaice fishing were superseded by newer and more efficient methods, and Dr. Petersen thought then that this meant "the end of the golden day for the fishing industry," and he had similar thoughts about the North Sea plaice fisheries. Now he confesses that later developments have shown that he was wrong. What has occurred in the two areas is much the same; the quantities of plaice taken per day's fishing by the old types of vessels were much greater than those now being taken by the newer boats fitted with much more efficient gear. Why? In both areas there was an " accumulated stock" of fish. Vessels of low fishing capacity could do well on such grounds.
How to remedy this "impoverishment"? There are two theories of regulation: (I) to raise more young plaice either by protecting the breeding fish so as to allow them to reproduce at least once in their lifetimes, or by artificial hatching, and (2) to legislate and otherwise deal with the fishery so as to increase the growth-rate of the plaice, because it is not merely a vast quantity of fish on the grounds that is desirable but rather an increased rate of production of plaice-flesh. An overcrowded ground may harbour small old plaice or young and relatively big ones. Plaice which do not grow at all consume from three to four times their own weight of food. In the Baltic there are fish of $32-36 \mathrm{~cm}$. in length which are $4-5$ years old as well as others of the same sizes but of 9-I 8 years old. The best policy is so to regulate the fishing as to increase the proportion of the younger, more rapidly-growing fish.

How to do this? The conditions in the North Sea illustrate the difficulty - and the remedy. If the Dogger Bank were an island surrounded by shallow water, vastly more plaice would grow to good marketable sizes than do now. As it is, the fishing is probably too intense and plaice are caught more rapidly than they can migrate out from the overcrowded grounds just off the Continental coasts. The restocking of the deeper parts, where the fish will grow well, from the nurseries (where they grow slowly) must keep pace with the depletion of these grounds. This means two kinds of measures: (I) size-limits in fishing, and (2) transplantation, both being modified according to the circumstances. If young plaice do not migrate out into favourable parts of the North Sea they must be assisted. Dr. Petersen himself made successful transplantation experiments in the Limfiord long ago, and more recently, English investigators have shown, beyond all doubt, that the same measures were practicable, and sure to be highly successful, in the North Sea.

The rationale of a continued and still more intensive exploitation of the fishing grounds is indicated by the scientific investigations. The transplantation experiments show which are the favourable grounds; growth-rates are known, and the work now in progress by the English investigators is giving results of value in regard to the supplies of food on the various grounds. The difficulties belong only to the practical working of the regulatory measures. Something like a scientific " nationalisation " of the deep-sea fishing industry appears to be necessary in the interest of an increased food supply, should the apprehensions of a failing stock be justified. It seems like a revolutionary proposal to suggest that permission to exploit the offshore fishing grounds should become necessary and that this permission should be accompanied by certain conditions, yet something of the kind may have to come in the near future. Meanwhile the scientific work in progress is affording the data whereby such proposals can materialise when the administrations are ready.

\section{Solar Radiation.}

VOLUME IV. of the Annals of the Astrophysical Observatory of the Smithsonian Institution contains the investigations on solar radiation made by the director, Prof. C. G. Abbot, assisted by F. E. Fowle, L. B. Aldrich, and others. The work in the Northern Hemisphere has been transferred from Mt. Wilson to Mt. Harqua Hala, Arizona; that in Chile from Calama to Mt. Montezuma. In I9I4 pyrheliometers were taken up to a height of $25 \mathrm{~km}$. by small balloons. The atmospheric pressure was $3 \mathrm{~cm}$. of mercury; the value of the solar constant indicated was $\mathrm{r} .84$ calories per $\mathrm{cm}^{2}{ }^{2}$, in good agreement with the adopted value.

Mr. Clayton compared the variations of solar radiation measured in I9I $3^{-1} 4$ with the temperature records in various parts of the world; he found a 
correlation that was positive in the Tropics and Polar regions, negative in the Temperate zones. $\mathrm{He}$ also found that the temperature in Argentina was correlated to the short-period variations of radiation observed in Chile, and he suggests that these changes have a tendency to recur in periods of 12 and 22 days. They are interpreted as being due to varying transparency of the solar atmosphere. Measures of the brightness of Saturn indicated similar variations, but with a time-interval proportional to the difference of longitude of Saturn and earth. This would be explained by the solar regions of high or low radiation being carried round by the sun's rotation.

The excess of radiation at sunspot maximum is explained by the greater activity of solar convection currents at that time; these bring hot matter from the interior to the surface, which more than balances the loss of heat in the spots themselves.

The mean state of transparency of the solar atmosphere is measured by observations of the radiation at different distances from the centre of the disc.
The contrast between centre and limbs is found to be greatest when the solar spot activity is greatest. On the other hand, the short-period increases of radiation are associated with less contrast between centre and limb.

The work also gives information on the transparency to radiation of different layers of our own atmosphere. "The atmosphere above II $\mathrm{km}$. contributes more than half the radiation of the earth viewed as a planet. . . . Nearly the entire output of radiation of the earth to space, more than $\frac{3}{4}$, arises from the atmosphere and clouds."

The albedo of a large white cloud in the sunshine was measured from a balloon above it and found to be 78 per cent. Prof. H. N. Russell's discussion of Müller's observations of the albedo of Venus gave the value 59 per cent. It is concluded that the clouds on Venus while general are not thick enough to give full cloud reflection except for oblique rays. 'The albedo of the earth seen from space is estimated as between 43 and 45 per cent.

\section{Botulism in Scotland.}

THE Scottish Board of Health has issued a very clear and interesting report on the circumstances attending the deaths of eight persons from botulism at Loch Maree in Ross-shire last year, and none of the vivid tragedy of the occurrence is lost in the telling by Dr. G. R. Leighton.

On August $\mathrm{I} 4, \mathrm{I} 922$, a number of guests stopping in the hotel went out for the day, and within a week six of them, as well as two of the attendant ghillies, were dead. Once some sort of food poisoning was suspected, the distribution of the fatalities between these living in the hotel and those living in their own homes in the neighbourhood at once implicated luncheon, the only meal taken in common, as the source of the poison, and further inquiries appeared to bring particular suspicion on a glass jar of wildduck paste out of which about a dozen of the sandwiches had been made. The empty jar was fortunately recovered, and Mr. Bruce White, at the University of Bristol, was able to show that the small fragments of paste left in it were intensely poisonous to mice, and from them to isolate the Bacillus botulinus itself. One of the ghillies was not hungry enough to eat all his sandwiches and took one home with him; when he fell ill next day and rumour suggested something wrong with the lunch his friends buried the sandwich, which was retrieved later and shown by animal experiment to be extremely toxic. A guest also failed in his appetite and threw the most part of a sandwich to a wagtail on the lake shore ; a month later Dr. Leighton found the decayed remains of a small bird among the stones.

There has, indeed, seldom been an outbreak of food poisoning in which the facts were so clear and so plainly verified. The only point of interest which the report fails to elucidate-and perhaps the facts could not be ascertained with complete accuracyis how many people ate any of the poisonous paste without having symptoms: it seems likely that there may have been about five.

As has lately been shown by Dr. K. F. Meyer of the University of California (NATURE, January 20, p. 95) $B$. botulinus is a widespread common inhabitant of the soil, and may often be found on fruits, vegetables, and other food-stuffs. Taken with food in any numbers that are reasonably possible it is harmless, and in this way differs sharply from the food poisoning bacilli of the Gaertner and Aertrycke group, which multiply inside the body and cause illness by producing a definite infection. $B$. botulinus is poisonous only if it has been able to grow for some time under favourable conditions outside the body and produce large quantities of its potent toxin ; man is poisoned by the toxin, not infected by the bacillus. Laboratory experiments show that the resting spores are exceptionally difficult to kill by heating. Considering, indeed, the wide distribution of the bacillus in Nature, the rarity of botulism is a remarkable testimony to the care with which potted meats and so on are usually prepared. Really efficient sterilisation is a secure preventive. The difficulty is that the glass containers, which the public æesthetically prefers, cannot be heated to a sufficiently high temperature without an undue proportion of breakages. There seems to be no good reason why they should not be prohibited and tins made compulsory.

\section{Building Construction Research.}

THREE reports on investigations connected with house construction and allied subjects have recently been issued by the Department of Scientific and Industrial Research. ${ }^{1}$

In the first of these, Mr. W. H. Wainwright gives some details of the cost of cottage building, and at the present time, when the cost of building is a very

1 Department of Scientific and Industrial Research. Building Research Board: Special Report No. 6, "A Graphical Cost Analysis of CottageBuilding." By W. H. Wainwright. Pp. iv $+8+20$ diagrams, $2 s$, $6 d$, net Building Research Board: Special Report No. 5, "Building in Cob and Pise de Terre: a Collection of Notes from Various Sources on the Construction Earth Valls." Pp. iv + Notes from Various Sources on the Construction of No. "Tests on Ranges and Cooking A ppliances"” Board: Special Report Extract from the Report of the Building Materials B. H. Barker. An Pp. vi $+55+15$ figs. $2 s$. 6 d. net. (London: H. M. Stationery Office, $\mathrm{x} 922$.) NO. 2786 , VOL. I I I ] vexed subject and development schemes have to be very carefully debated owing to financial stringency, such information should be valuable. It is only by careful analysis in the matter of outlay that organisation can be improved and economy effected, and those engaged in large building works will find in these tables much interesting matter. The diagrams are partly compiled from data collected by the Ministry of Health; some are calculating graphics which should save time and do something to popularise graphic methods among technicians, while others show the rise and fall of prices in labour and materials from I9I.4 to 1922 and are of general application.

Mr. Weller in his editorial introduction anticipates 